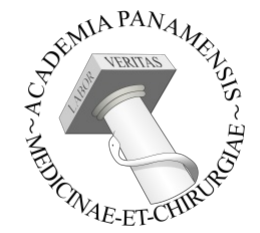

\title{
Editorial
}

\section{La Medicina Sigue, a Pesar de La Pandemia por COVID-19}

\section{[Medicine Continues, Despite Pandemic by COVID-19]}

\section{Cuero César, APMC}

Palabras Claves: Sistema de

salud, pandemia, recursos.

Keywords: Health system, pandemic, resources.

Correspondencia a:

Cesar Cuero

Correo electrónico:

ccuero@cwpanama.net

Publicado: 15 de junio. 2021.
No hay duda que la presente pandemia por COVID-19 ha hecho estragos en todos los países del mundo. En algunos en forma desmedida, pero en todos trastocando el sistema de salud nacional, desmejorando notablemente la economía y cambiando la rutina diaria de la gente, dejando secuelas de todo tipo, tanto clínica como emocional.

Esta pandemia si bien inicialmente afectó principalmente a los adultos mayores, en la actualidad está atacando a la población más joven, aumentando el número de fallecidos en este segmento poblacional. No hay duda que esta pandemia ha desnudado las falencias de un sistema de salud débil, desorganizado, carente de recursos y muy mal administrado, realidad que se agudiza más, en tanto menos recursos económicos tenga el país.

Y es precisamente esto último lo que más preocupa. Resulta que todos los países han tenido que dedicar recursos que se tenían para otros fines, al manejo de los afectados por el COVID-19, y han tenido necesidad de recurrir a la banca y entidades monetarias internacionales, a solicitar préstamo de dinero, en cantidades preocupantes, comprometiendo el futuro y la estabilidad económica de sus conciudadanos, por varias generaciones.

Muy a pesar de lo antes señalado, en todos los países de América Latina y demás regiones del mundo, el resto de las enfermedades que normalmente afecta a la población siguen mermando el estado de salud de todos, sin que se pueda encontrar fácilmente la atención médica necesaria para su mal, que no tiene nada que ver con el COVID-19.

En todas partes el escenario es lamentable y desgarrador. Salas hospitalarias saturadas, unidades de cuidados especiales sin camas libres, hospitales enteros sumergidos en el caos, incapaces de dar respuesta a la persona que acude a ellos por una afección cardíaca o pulmonar que requiere cuidados del nivel más especializado.

Por otro lado, la carencia de personal general, y especializado, que se dedique a atender al resto de los enfermos que no han sido afectados por el COVID-19, acrecienta la crisis. Esto retrata de cuerpo entero el decadente y paupérrimo sistema de salud de nuestros países. Es peligroso y lamentable enfermarse en estos tiempos. Y es muy lamentable aceptar que esta realidad se traslada al campo de la medicina privada. Es decir, en algunos países, ni siquiera hace diferencia el tener cobertura médica privada, porque simplemente no hay camas disponibles.

La medicina sigue, a pesar de la pandemia, pero sin adecuada planificación, con la marcada carencia de recurso económico y humano. A donde llegaremos, aún está por verse.

\section{Cesan Cuevo}

Editor en Jefe 